Int. J. Dev. Biol. 52: 345-352 (2008)

doi: $10.1387 / \mathrm{ijdb} .072455 \mathrm{cc}$

\title{
Spatiotemporal clustering of cell death in the avian forebrain proliferative zone
}

\author{
CHRISTINE J. CHARVET* and GEORG F. STRIEDTER \\ Department of Neurobiology and Behavior, University of California, Irvine, USA
}

\begin{abstract}
The extent to which programmed cell death is the fate of proliferative, rather than post-mitotic, cells remains controversial, but a preponderance of evidence suggests that at least some cells within the brain's proliferative zone die during mammalian brain development. One major unresolved question is the extent to which cell death in the proliferative zone is spatiotemporally patterned. In order to answer this question we used the terminal dUTP nick end labeling (TUNEL) method to stain apoptotic cells in the forebrain of chicken embryos at relatively early stages of brain development (Hamburger-Hamilton stages 19-32). Our principal finding is that most of the TUNEL-positive cells within the brain's proliferative zone are concentrated into distinct clusters, whose location varies with developmental stage. At stage 19, many TUNEL+cells are found within the basal synencephalon, just below where the forebrain's first neurons are located. At stages 24-26, numerous TUNEL+ cells are located within the preoptic area and along the optic stalk. After stage 26, TUNEL labeling is prominent in two telencephalic areas: the thin dorsomedial telencephalon and the thickest portions of the telencephalon's lateral walls (i.e. the dorsal ventricular ridge). Collectively, the observed pattern of TUNEL staining suggests that cell death in the proliferative zone plays a substantial role in shaping the forebrain. In addition, cell death in the proliferative zone may be related to cell cycle exit.
\end{abstract}

KEY WORDS: apoptosis, chick, neurogenesis, BrdU

\section{Introduction}

During normal brain and spinal cord development many cells undergo apoptotic cell death (e.g., Glücksmann, 1951; Hamburger \& Oppenheim, 1982). Apoptotic cells are sometimes identified morphologically (see Homma et al., 1994) or with antibodies against proteins that tend to be expressed in apoptotic cells. Today, the most widely used technique for identifying apoptotic cells is terminal dUTP nick end labeling (TUNEL), which labels DNA fragments generated during apoptosis (Gavrieli et al., 1992; Kelly et al., 2003). TUNEL staining is widely regarded as the "gold standard" criterion of apoptotic death (Kelly et al., 2003). A more recent technique for detecting apoptosis is in situ end labeling plus (ISEL+), which is related to TUNEL but is more sensitive (Blaschke et al., 1996).

Traditionally, most apoptotic death was thought to occur in post-proliferative cells that have begun to form synaptic connections (Katz \& Lasek, 1978; Oppenheim, 1985; Yaginuma et al., 1996; Clarke et al., 1998; Bennet et al., 2002; Buss et al., 2006). However, several studies have suggested that apoptosis may occur also in proliferating precursors (e.g., Nikolapopoulou et al., 2006). Most notably, the ISEL+ method labeled $>50 \%$ of the proliferative zone cells in the cortex of mice between E14 and E18, when most neocortical neurons are born (Blaschke et al., $1996,1998)$. With such a high level of proliferative zone cell death it is difficult to imagine how brains could grow at all (Gilmore et al., 2000). Furthermore, models of cortical development that account for rates of cell division, cycle exit, and debris clearance suggest that ISEL+ significantly overestimates the degree of proliferative cell death (Gohlke et al., 2004; see also Cai et al., 2002). TUNEL also labels at least some cells in the proliferative zone of the rodent neocortex (Thomaidou et al., 1997), and manipulations

\footnotetext{
Abbreviations used in this paper: DI, diencephalon; DT, dorsal thalamus; DVR, dorsal ventricular ridge; ET, epithalamus; Hip, hippocampal formation; Hy, hypothalamus; ISEL, in situ end labeling; Med, medulla; Mes, mesenchyme; MZ, mantle zone; OSt, optic stalk; Syn, Synencephalon; Tec, optic tectum; Teg, tegmentum; Tel, telencephalon; PoA, preoptic area; PP, posterior parencephalon; Ret, retina; Rh, rhombencephalon; TUNEL, terminal dUTP nick end labeling; Vent, ventricle; VZ, ventricular zone.
}

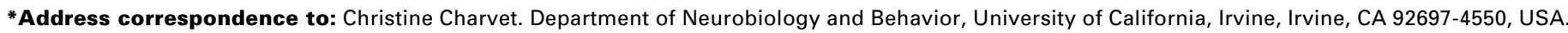
Fax: +1-949-824-2447. e-mail: ccharvet@uci.edu Web: http://striedterlab.bio.uci.edu/StriedterLaboratory/index.html
}

Accepted: 8th September 2007. Published online: 28th January 2008. Edited by Edward de Robertis. 
that reduce proliferative cell death enhance cortical growth (Kingsbury et al., 2003; Depaepe et al., 2005; Inglis-Broadgate et al., 2005). Therefore, a prudent conclusion is that at least some proliferative zone cell death occurs in the neocortex (Gohlke et al., 2004; Wilkie et al., 2004). Further research is needed to clarify the rate of that proliferative zone cell death and why ISEL+ appears to stain some cells that do not die (e.g., see Gilmore et al., 2000).

It is also unclear to what extent proliferative zone cell death is spatiotemporally patterned. ISEL+ shows a fairly uniform pattern of cell death within the proliferative zone of the mouse neocortex (Blaschke et al., 1996) but exhibits a ventrolateral-dorsomedial gradient (Blaschke et al., 1998). ISEL+ staining has also been reported in brain regions other than the neocortex (Blaschke etal., 1998), but spatiotemporal variations in that extracortical staining have not been described. Studies using TUNEL likewise focused on the neocortex (Thomaidou et al., 1997) or examined small extra-cortical regions (Navascués et al., 1988; Furuta et al., 1997). A few purely histological studies were broader in spatial scope but focused on very young embryos (Källén, 1955). Collectively, these studies provide at best a very uncertain, partial mosaic image of how cell death in the brain's proliferative regions varies across brain regions, time and space.

Although work on proliferative zone cell death has focused on mammals, comparable data exist also for chickens. ISEL+ revealed a spatiotemporal pattern of proliferative and post-proliferative cell death in the optic tectum (Zhang \& Galileo, 1998). TUNEL and histological staining revealed regions of proliferative zone cell death in the chicken's spinal cord“(Homma et al., 1994) and hindbrain (Lawson et al., 1999). A more broadly focused study (Hirata \& Hall, 2000) reported that TUNEL staining in the midbrain and forebrain of chick embryos is restricted to early development (stages 8-15) but offers few additional details. Another study describes elevated apoptosis in the chicken forebrain at later stages of development (Hyndman \& Zamenhof, 1978). However, this study employed homogenized tissue and therefore lacked spatial resolution. Thus, the work on birds also presents only a partial view of how proliferative zone cell death varies in time and space.

The present study derscribes the spatiotemporal variation in proliferative zone cell death within the embryonic chicken brain, as assayed by TUNEL. It focuses mainly on the developing forebrain and focuses on stages 19-32 (Hamburger \& Hamilton, 1951), because this is the

Fig. 1. Schematic charting of TUNEL-positive cells and cell fragments in the brain of chick embryos at stage 19. (A) Lateral view of the entire brain, showing the approximate planes of the sections illustrated in (B$D$ ). TUNEL staining is most pronounced in the floor of the synencephalon (Syn) where a post-proliferative mantle zone $(\mathrm{MZ})$ is well developed $(\mathbf{B}, \mathbf{C})$ and in the preoptic area (PoA) just rostral to the optic stalks (OSt) (D). Boundaries of some major brain regions, such as the telencephalon (Tel) and optic tectum (Tec) are demarcated by dashed lines coursing perpendicular to the ventricular surface. The dashed rectangles delineate regions that are illustrated further in Fig. 2. Scale bar for $B-D, 100 \mu m$. major period of neurogenesis in the avian forebrain (Tsai et al., 1981). The present study shows that cell death in the proliferative zones of the avian forebrain has a limited distribution in space and time.

\section{Results}

At the stages we examined, TUNEL labeling is concentrated in specific brain regions, and this spatial pattern varies across the stages of development. In the following paragraphs, the patterns of TUNEL labeling are described chronologically, starting with stage 19 and ending with stage 32 .

At stage 19 the chicken brain consists primarily of a cell-dense proliferative ventricular zone (VZ). Most brain regions at this age harbor a few post-proliferative cells superficial to the VZ, but the basal synencephalon exhibits an extensive post-proliferative mantle zone (MZ; Puelles et al., 1987). Most TUNEL+ cells at stage 19 are found in the VZ of the basal synencephalon (Fig. 1) adjacent to the burgeoning $M Z$, which stains heavily with TUJ-1 (Fig. 2). Some TUNEL+ cells are also located just rostral to the basal synencephalic cells, in the basal portion of the posterior parencephalon (Fig. 1C). A third cluster of TUNEL+ cells lies just rostral to the evaginations of the optic stalks, in the $V Z$ of the presumptive preoptic area (PoA; Fig. 1D).

At stage 24 (data not shown), TUNEL labeling is dense in the VZ of the preoptic area. Labeled cells are also found in the presumptive optic chiasm and along the optic stalks. The density of labeled cells is also high in ventricular zone of the telencephalic midline.

At stage 26 elevated levels of cell death were observed along the telencephalic midline and in the preoptic area (Figs. 2, 3). The latter labeling is heaviest in the VZ, but numerous TUNEL+ cells were also observed in the adjacent MZ (Figs. 2D). TUNEL labeling was also seen in the VZ at the center of the developing
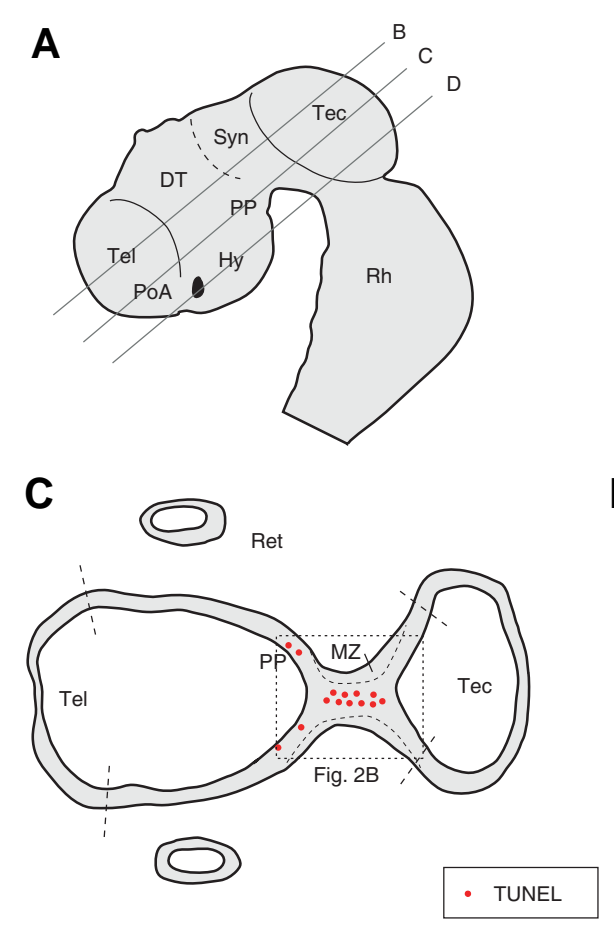

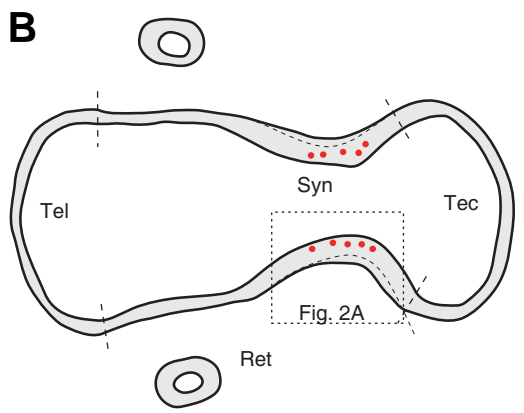

D

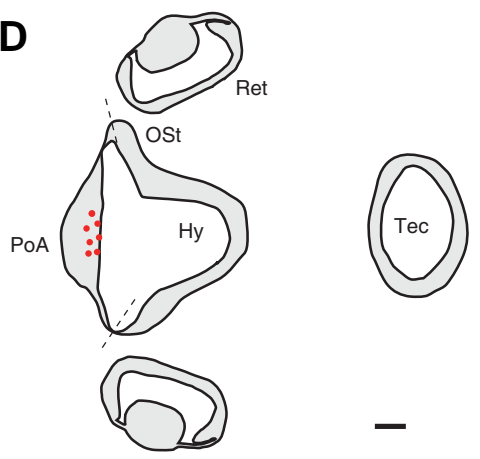


dorsal ventricular ridge (DVR; Fig. 3B), which corresponds, at least in part, to the ganglionic eminences of embryonic mammal brains. A few TUNEL+ cells were also noted in the relatively thin regions of the rostral and dorsal telencephalon. Finally, some cells were labeled in the VZ of the basal synencephalon and posterior parencephalon (Fig. 3B).

At stage 28 (data not shown) TUNEL+ cells lie mainly in two regions of the telencephalon. First, labeled cells are scattered throughout the rostral half of the telencephalon's thin medial wall, which has a thin MZ that stains more heavily with TUJ-1 at this stage than at stage 26 . Second, TUNEL+ cells are concentrated in the central region of the DVR. Within the DVR, TUNEL staining extends across both the VZ and the MZ.

TUNEL+ cells are more widespread at stage 30 than at stage 28 . Labeling is extensive in the thin medial telencephalic wall, but now extends also into the telencephalon's posterior pole (Fig. 4). Within that caudal pole, which dorsally includes the presumptive hippocampal formation, the labeled cells are found primarily in the $M Z$, although some $V Z$ cells are likewise labeled. Outside the telencephalon, labeled cells are located primarily along the tectal midline (Figs. $4 \mathrm{~B}-\mathrm{F}$ ), in the tegmentum and posterior diencephalon (Figs. 4C-E), in the most ventral hypothalamus (Fig. $4 \mathrm{H}$ ), and in the medulla (Fig. 4H). The labeling in these regions is also concentrated in the $M Z$, except in the tectal midline, where the $\mathrm{MZ}$ is minimal.

The pattern of TUNEL staining at stage 32 (Fig. 5) is generally similar to that at stage 30 , except that large numbers of TUNEL+ cells are found also in the anterior diencephalon, including the presumptive dorsal thalamus (Figs. 5D-E). Some of the heaviest labeling at this stage is in the posterior telencephaIon, particularly in the developing hippocampal formation (Fig. 5B). Virtually all of the TUNEL labeling at stage 32 is limited to the $M Z$, as the VZ in most regions has thinned dramatically. TUJ-1 staining in the hippocampal formation, in the medial telencephalic wall, and in the tectal midline is elevated at this stage relative to stage 28 (data not shown).

Cumulative BrdU labeling at stage 32 revealed a significant reduction in the percentage of proliferating (i.e., BrdU+) cells in the VZ of the telencephalic

Fig. 3. Charting of TUNEL-positive cells in the brains of chick embryos at stage $\mathbf{2 6}$. Labeling at this stage is most prominent along the telencephalic midline and in the preoptic region. Conventions are the same as for Fig. 1.

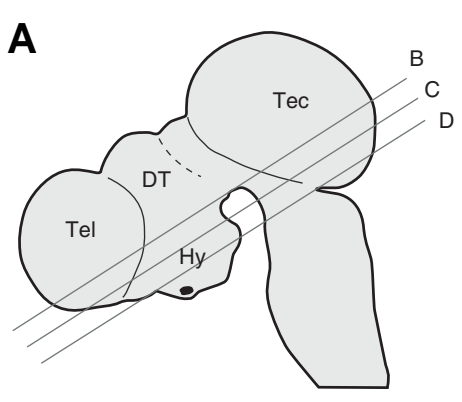

C
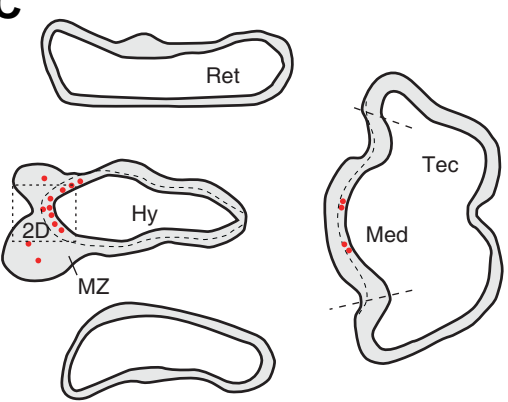
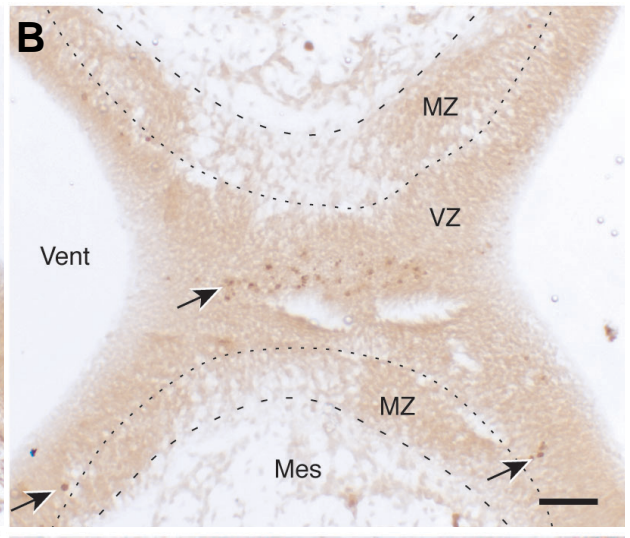

D

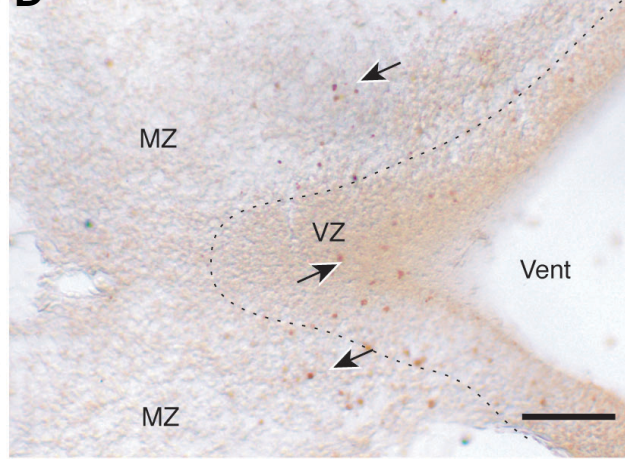

J-1-positive cells in the basal synencephalon of stage 19 (A-B) and telencephalon of stage 26 embryos (C-D). At stage 19, no TUNEL+ cells were the post-proliferative mantle zone (between the long and short dashed lines, denoted by an in (A) and by $M Z$ in (B). Insert in (A) shows that the mantle zone superficial to the basal illin porrows point to labeled cells in the The boundary between $M Z$ and $V Z$ is indicated by the short dashed line. Scale bar, $50 \mu \mathrm{m}$. 
A

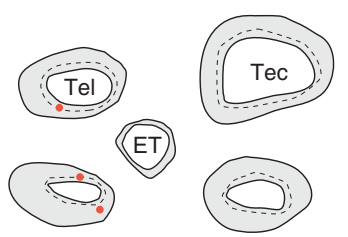

C

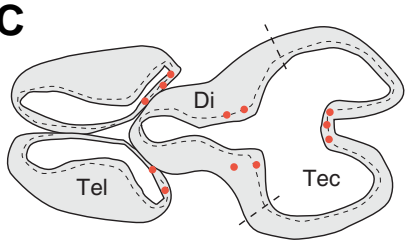

E

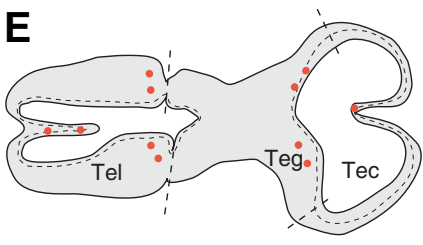

G

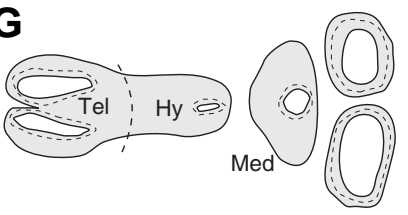

B

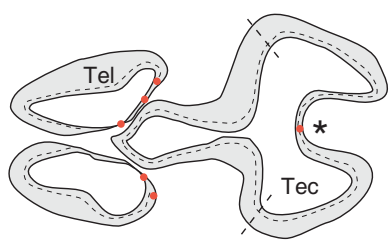

D

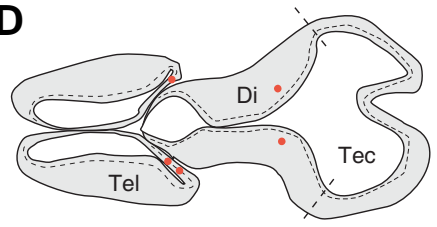

$\mathbf{F}$

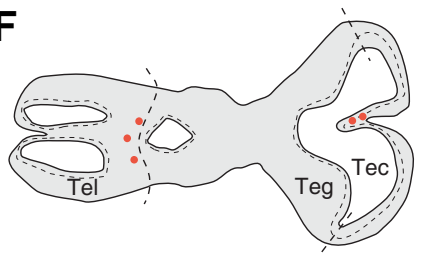

H

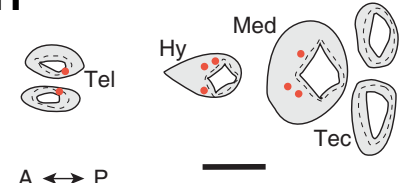

A

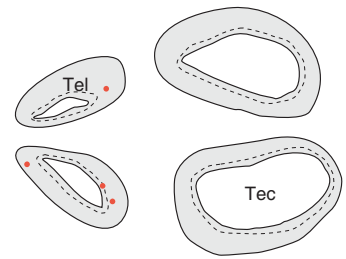

C

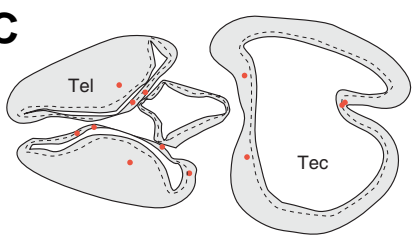

E

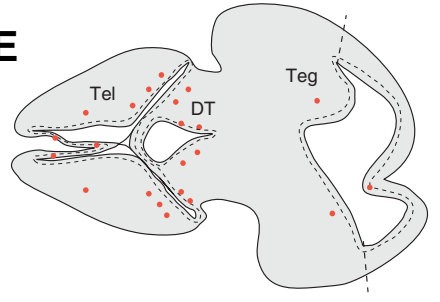

G

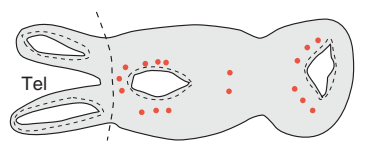

B

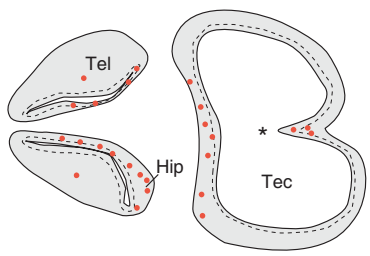

D

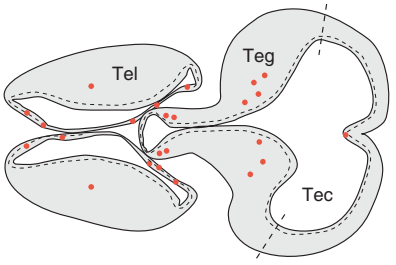

$\mathbf{F}$

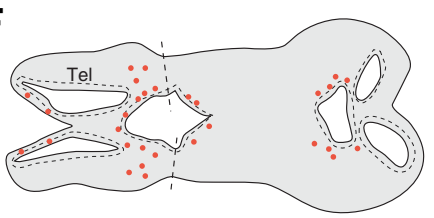

H

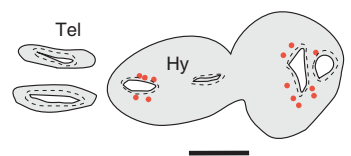

Fig. 4 (Left). Charting of TUNEL-positive cells in the brains of chick embryos at stage 30. Asterisk in (B) marks the tectal midline. Scale bar, 1 mm.

Fig. 5 (Right). Charting of TUNEL-positive cells in the brains of chick embryos at stage 32. Asterisk in (B) marks the tectal midline. Scale bar, 1 mm.

and tectal midlines (Supplementary Fig. 1). Specifically, the proportion of all VZ cells that is BrdU+ (i.e., the growth fraction) is significantly lower in the tectal midline than it is $1 \mathrm{~mm}$ or $2 \mathrm{~mm}$ away from the tectal midline (unpaired T-tests; $t=-9.6,-8.1 ; p$ $<.01)$. Similarly, the growth fraction along the telencephalic midline is reduced relative to the growth fraction of the rostral telencephalon (unpaired T-test; $t=-6.2 ; p<.01$ ).

\section{Discussion}

The present study relies on the TUNEL method, which can yield false positives and negatives (e.g., Labat-Moleur et al., 1998). This problem was minimized by using a well tested version of the TUNEL technique that incorporates a step to stop the enzymatic reaction and, thereby, minimizes false positive results (Baima \& Sticherling, 2002). It is, however, likely that our technique fails to label some cells at early stages of apoptosis (Kelly et al., 2003). Therefore, the present study documents only the major patterns of relative cell death and should not be read as evidence against more subtle variations in proliferative cell death.

The main conclusion of the present study is that the distribution of TUNEL labeling, and hence of probable apoptosis, in the proliferative regions of the forebrain in chick embryos (between stages 19 and 32) is spatially and temporally heterogeneous. This finding is surprising insofar as previous studies of the mammalian telencephalon have generally reported fairly uniform spatial pat- terns of proliferative zone cell death (Blaschke et al., 1996; Thomaidou et al., 1997; Blaschke et al., 1998; Rakic \& Zecevic, 2000). However, our finding is consistent with several reports on very young mammalian and avian embryos, which show that dying cells are clustered in both space and time (Källén, 1955; Homma etal., 1994; Lawson etal., 1999; Hirata \& Hall, 2000). The simplest way to reconcile these discrepant reports is to hypothesize that spatial heterogeneities are easily obscured when highly sensitive techniques, such as ISEL+ or some versions of TUNEL (Baima \& Sticherling, 2002), are used to demonstrate apoptosis. Another possibility is that the apparent degree of spatial uniformity tends to increase as a study's spatial focus narrows. Because the present study's focus was broad (the entire forebrain), and its staining technique conservative, spatial heterogeneities were readily detectable. For purposes of discussion, we recognize four major clusters of proliferative zone cell death in our embryos.

One region of enhanced proliferative zone cell death lies just rostral and ventral to the evagination of the optic tracts at stages 19-26. This preoptic cell death cluster most likely corresponds to what Källén (1965) called the suboptic necrotic centers, which in spite of their name exhibit several hallmarks of apoptosis (Navascués et al., 1988). Because these suboptic necrotic centers begin to develop at or around stage 14 (Navascués et al., 1988), the cluster we describe most likely represents their terminal phase, when the initially bilateral centers are fusing, or have 
fused, across the midline. Although the function of proliferative zone cell death in this region remains debatable, it is worth noting that optic tract axons begin crossing through this region around stage 20 (Navascués et al., 1987). Perhaps the dying cells make room for axons to grow through (Schook, 1982). Alternatively, the suboptic necrotic centers may guide the growing optic tract axons (Navascués et al., 1988).

The second noteworthy cluster of proliferative zone cell death lies within the basal synencephalon at stage 19. To our knowledge, this cluster has not previously been described. An interesting aspect of this basal synencephalic cell death cluster is that it lies precisely where the forebrain first develops a thick mantle zone of post-proliferative cells. This region corresponds, at least in part, to the basal synencephalic region of acetylcholinesterasepositive neuroblasts described by Puelles et al. (1987) in chickens at slightly younger stages of development. Also intriguing is that the basal synencephalic cluster of apoptotic cells lies where the brain's cervical flexure is maximal. This correlation suggests that proliferative zone cell death might contribute to the formation of the cervical flexure by causing the basal synencephalon to expand more slowly than the dorsal synencephalon (Takamatsu \& Fujita, 1987). This idea is speculative, however, and alternative mechanisms should be considered (Flynn et al., 1991).

The third region of high proliferative zone cell death is the dorsomedial telencephalon at stages 24-30. Initially this zone of dying cells is limited to the midline of the anterior telencephalon, which is notably thinner than the adjacent neuroepithelium of the telencephalic hemispheres. This pattern of cell death is similar to that seen in the dorsal telencephalic midline of mammalian embryos (Furuta et al., 1997; Currle et al., 2005). By stage 30, however, the zone of dying cells and TUJ-1+ cells in birds expands to include most of the telencephalon's medial wall, including the posterior pole. This broad expansion of the dorsomedial telencephalic cell death zone has not, as far as we know, been described in mammals.

Fourth, cell death is elevated at stages $26-28$ in the proliferative zone of the thickened lateral telencephalic wall, which comprises the DVR. This pattern resembles the mammalian condition, because the avian DVR is probably homologous to several mammalian structures, including the neocortex and the ganglionic eminences (Striedter, 1997; Reiner et al., 2004; Jarvis et al., 2005). Both structures show elevated levels of proliferative cell death at this stage of development (Thomaidou et al., 1997; Blaschke et al., 1998; Rakic \& Zecevic, 2000). However, in birds the proliferative zone cell death is most pronounced in the central, thickest region of the DVR and falls off towards the DVR's margins. Such a pattern has not been reported in the neocortex or the ganglionic eminence of mammals, and it has not been previously described in birds.

An interesting question is why the cells in these four focal brain regions adopt their apoptotic fate. An emerging theme in the literature on proliferative cell death is that apoptosis is maximal around the time, or just after, the proliferating cells exit the cell cycle (Blaschke et al., 1996; Thomaidou et al., 1997; Blaschke et al., 1998; Hensey \& Gautier, 1998). To explain this correlation one might suggest that apoptosis eliminates cells that failed to exit or re-enter the cell cycle properly, exited prematurely, or adopted an improper phenotype after leaving the cell cycle (Homma et al., 1994; Voyvodic, 1996; Gilmore etal., 2000; Oishi et al., 2004; Yeo
\& Gautier, 2004; Becker \& Bonni, 2005). The present study was not designed to discriminate between these possibilities, but our results are generally consistent with the notion that proliferative zone cell death is linked to cell cycle exit.

For example, the cluster of dying cells in the basal synencephalon coincides with a focal increase in the generation of young neuroblasts. It is also interesting to note that in both the basal synencephalon and in the lateral telencephalon, proliferative zone cell death tends to increase with the thickness of the adjacent mantle zone. This pattern would be predicted if the likelihood that a precursor cell will die increases as it approaches, traverses, or emerges from the decision to exit the proliferative cell cycle. Cell death in the proliferative zone of the dorsomedial telencephalon may also be associated with cell cycle exit because our cumulative BrdU labeling experiments, which label most proliferating cells, reveal that the proportion of cells within the proliferative zone that are proliferating is significantly reduced in the thin dorsomedial wall of the telencephalon at stage 32. The same pattern is apparent in the thin dorsal midline of the optic tectum at stage 32. These two regions also exhibit thin bands of TUJ-1+ cells that are not observed at stage 28 . These findings suggest that the focal thinning of the brain's proliferative zone is associated with many cells leaving the cell cycle and then remaining in the proliferative zone, rather than migrating out to form a separate mantle zone.

The present study also raises questions about the functional significance of apoptosis in the brain's proliferative zones. Most previous reports on cell death in the brain's proliferative zone have emphasized its potential role in error correction or phenotypic selection (Voyvodic, 1996). Such functions would be called histiogenetic according to Glücksmann's classic scheme (Glücksmann, 1951). In addition, our data suggest that cell death in the proliferative zones may play a role in morphogenesis. Most intriguing is that cell death in the dorsal midline of both telencephalon and optic tectum is roughly coincident with their transformation from unitary vesicles into bilobar hemispheres. To the extent that cell death reduces growth along the dorsal midlines, it would facilitate those divisions. It is also interesting to speculate that cell death in the basal synencephalon and preoptic region may help to increase the forebrain's curvature (Takamatsu \& Fujita, 1987). Although these functions all remain highly debatable, the debate itself implies that cell death in young embryonic brains is probably not simply "noise" - the consequence of random errors in development - but part of a complex program that helps to establish some crucial aspects of the brain's early form and eventual function.

\section{Materials and Methods}

Fertile eggs of domestic chickens (Gallus gallus domesticus, White Leghorn strain) were obtained from a commercial supplier and incubated at $37^{\circ} \mathrm{C}$ in an incubator (GB-1; Avey Incubator, Evergreen, CO). Twentyfour embryos were collected and staged according to the criteria developed by Hamburger and Hamilton (1951). We limited our analysis to the period from 3 to 8 days of incubation and a regularly spaced subset of stages, namely stages $19(n=2), 24(n=5), 26(n=5), 28(n=3), 30(n=4)$ and $32(n=5)$. Thus, our analysis covers at least the first half of the neurogenetic period in the chicken's forebrain (Tsai et al., 1981).

Embryos were immersion fixed in $4 \%$ buffered paraformaldehyde. The next day, each embryo was dehydrated through a graded series of 
alcohols, toluene and embedded in paraffin (Paraplast X-tra; Fisher Scientific). The embedded brains were cut horizontally at a thickness of $18 \mu \mathrm{m}$. Every fifth section was mounted for stage 19 and every twelfth for stages 24-32. Additional sections through the ventral forebrain were collected for stages 24 and 26.

The colorimetric FragEI DNA Fragmentation Detection Kit from Calbiochem (EMD Biosciences) was used to visualize apoptotic cell death. This kit uses terminal deoxynucleotidyl transferase (TdT), biotinylated nucleotides, streptavidin horseradish peroxidase (HRP), and diaminobenzidine (DAB) to label the exposed DNA fragments generated during apoptosis. It also includes a "stop solution" that inhibits the TdT enzyme, and greatly improves the kit's consistency and decreases the rate of false positive staining (Baima and Sticherling, 2002).

All processing steps were highly standardized. First, the sections were deparaffinized and hydrated to deionized water. They were then incubated in proteinase $\mathrm{K}$ for 17 minutes at room temperature (26-28으). After rinsing the sections in tris-buffered saline $(20 \mathrm{mM}$ Tris $\mathrm{pH} 7.6 ; 140 \mathrm{mM}$ $\mathrm{NaCl}$ ), they were incubated in a solution of $10 \%$ hydrogen peroxide and $90 \%$ methanol for 5 minutes to quench any endogenous peroxidases. After rinsing again, the sections were incubated in a TdT equilibration buffer for 18 minutes. Then, the sections were covered with the reaction mix and incubated at $37^{\circ} \mathrm{C}$ in a humidified chamber. After 90 minutes the TdT reaction was stopped with a stop solution. After washing, the sections were incubated with streptavidin HRP for 30 minutes, rinsed, reacted with DAB for 5-8 minutes, dehydrated and coverslipped. Adjacent sections were counterstained to identify histological boundaries.

The stained sections were examined through an Olympus BH2 microscope and photographed with a digital color camera (Spot Insight; Diagnostic Instruments, Sterling Heights, MI). All photographic images were adjusted only for contrast and color balance. Chartings that show the approximate numbers and locations of labeled cells were generated by tracing the outlines of selected sections from low-magnification images.

To determine the extent to which post-proliferative cells remain within a region's proliferative zone, we performed cumulative labeling with bromodeoxyuridine (BrdU). Any cells that were BrdU-negative in the proliferative zone after cumulative labeling were interpreted as postproliferative. Embryos at stage $32(n=4)$ were infused with $10 \mu \mathrm{l}$ of $\mathrm{BrdU}$ $(50 \mu \mathrm{g} / \mathrm{g}$; Sigma, St Louis, MO) applied directly onto the embryo at 2 hour intervals and fixed in methacarn after 8 hours. For BrdU detection, sections were denatured with $0.5 \mathrm{M} \mathrm{HCl}$ for thirty minutes, incubated with anti-BrdU (IU4; 1:100; Caltag, Burmingame, CA), and reacted with the biotinylated anti-mouse IgG (1:200; Vector, Burlingame, CA). BrdUlabeled and unlabeled cells were counted in $60 \mu \mathrm{m}$ wide boxes placed over the proliferative zones at the tectal midline, 1 and $2 \mathrm{~mm}$ distal to the tectal midline, at the telencephalic midline, and in the rostral telencephalon.

To determine neurogensis onset an antibody against TUJ-1 was used to label immature neurons in sections adjacent to those stained with TUNEL (Geisert \& Frankfurter, 1989). Sections were incubated with the monoclonal TUJ-1 antibody (1:500; Chemicon, Temecula, CA) and with biotinylated anti-mouse IgG (1:200; Vector, Burlingame, CA).

\section{Acknowledgements \\ We would like to thank Mathew Korn, Shyam Srinivasan and Dr. David Weisbart for their helpful comments on the manuscript. We would also like to thank Lian Lim for tissue processing. This work was supported in part by IBN-0236184 from the National Science Foundation.}

\section{References}

BAIMA, B. and STICHERLING, M. (2002). How specific is the TUNEL reaction? Am $J$ Dermatopath 24: 130-134.

BECKER, E. B. E. and BONNI, A. (2005). Beyond proliferation - cell cycle control of neuronal survival and differentiation in the developing mammalian brain. Sem Cell Dev Bio/16:439-448.
BENNET, M. R., GIBSON, W. G. and LEMON, G. (2002). Neuronal cell death, nerve growth factor and neurotrophic models: 50 years on. Autonomic Neuroscience: Basic \& Clinical 95:1-23.

BLASCHKE, A. J., WEINER, J.A., W. and CHUN, J. (1998). Programmed cell death is a universal feature of embryonic and postnatal neuroproliferative regions throughout the central nervous system. J Comp Neuro/396:39-50.

BLASCHKE, A. J., STALEY, K. and CHUN, J. (1996). Widespread programmed cell death in proliferative and postmitotic regions of the fetal cerebral cortex. Development 122:1165-1174.

BUSS, R. R., SUN, W. and OPPENHEIM, R. W. (2006). Adaptive roles of programmed cell death during nervous system development. Annu Rev Neurosci 29:1-35.

CAI, L., HAYES, N. L., TAKAHASHI, T., CAVINESS, V. S. J. and NOWAKOWSKI, R.S. (2002). Size distribution of retrovirally marked lineages matches prediction from population measurements of cell cycle behavior. JNeurosci Res 69:731744.

ClARKE, P., POSADA, A., PRIMI, M.P. and CASTAGNE, V. (1998). Neuronal death in the central nervous system during development. Biomedecine \& Pharmacotherapy 52: 356-362.

CURRLE, D. S., CHENG, X., HSU, C.-M. and MONUKI, E. S. (2005). Direct and indirect roles of CNS dorsal midline cells in choroid plexus epithelia formation. Development 132:3549-3559.

DEPAEPE, V., SUAREZ-GONZALEZ, N., DUFOUR, A., PASSANTE, L., GORSKI, J. A., JONES, K. R., LEDENT, C. and VANDERHAEGHEN, P. (2005). Ephrin signalling controls brain size by regulating apoptosis of neural progenitors. Nature 435:1244-1250.

FLYNN, M. E., PIKALOW, A. S., KIMMELMAN, R. S. and SEARLS, R. L. (1991). The mechanism of cervical flexure formation in the chick. Anat Embryol 184:411-420.

FURUTA, Y., PISTON, D. W. and HOGAN, B. L. M. (1997). Bone morphogenetic proteins (BMPs) as regulators of dorsal forebrain development. Development 124:2203-2212.

GAVRIELI, Y., SHERMAN, Y. and BEN-SASSON, S. (1992). Identification of programmed cell death in situ via specific labeling of nuclear DNA fragmentation. J Cell Bio/119:493-501.

GEISERT, E.E. and FRANKFURTER, A. (1989). The neuronal response to injury as visualised by the immunostaining of class III beta-tubulin in the rat. Neurosi Lett 102: 137-141.

GILMORE, E. C., NOWAKOWSKI, R. S., CAVINESS, V. S. J. and HERRUP, K. (2000). Cell birth, cell death, cell diversity and DNA breaks: how do they all fit together. Trends Neurosci23:100-104.

GLÜCKSMANN, A. (1951). Cell death in normal vertebrate ontogeny. Biol Reviews of the Cambridge Philosoph Soc 26:59-86.

GOHLKE, J. M., GRIFFITH, W. C. and FAUSTMANN, E. M. (2004). The role of cell death during neocortical neurogenesis and synaptogenesis: implications from a computational model for the rat and mouse. Dev Brain Res 151:43-54.

HAMBURGER, V. and HAMILTON, H. L. (1951). A series of normal stages in the development of the chick embryo. J Morpho/88:231-272.

HAMBURGER, V. and OPPENHEIM, R. W. (1982). Naturally occurring neuronal death in vertebrates. Neurosci Commentaries 1:39-55.

HENSEY, C. and GAUTIER, J. (1998). Programmed cell death during Xenopus development: a spatiotemporal analysis. Dev Bio/203:36-48.

HIRATA, M. and HALL, B. K. (2000). Temporospatial patterns of apoptosis in chick embryos during the morphogenetic period of development. Int $\mathcal{J}$ Dev Biol 44:757-768.

HOMMA, S., YAGINUMA, H. and OPPENHEIM, R. W. (1994). Programmed cell death during the earliest stages of spinal cord development in the chick embryo: a possible means of early phenotypic selection. J Comp Neuro/345:377-395.

HYNDMAN, A. G. and ZAMENHOF, S. (1978). Cell proliferation and cell death in the cerebral hemispheres of developing chick embryos. Dev Neurosci 1:216225.

INGLIS-BROADGATE, S. L., THOMSON, R. E., PELLICANO, F., TARTAGLIA, M. A., PONTIKIS, C. C., COOPER, J. D. and IWATA, T. (2005). FGFR3 regulates brain size by controlling progenitor cell proliferation and apoptosis during embryonic development. Dev Bio/279:73-85.

JARVIS, E. D., GUNTURKUN, O., BRUCE, L., CSILLAG, A., KARTEN, H., KUENZEL, 
W., MEDINA, L., PAXINOS, G., PERKEL, D. J., SHIMIZU, T., STRIEDTER, G., WILD, J. M., BALL, G. F., DUGAS-FORD, J., DURAND, S. E., HOUGH, G. E., HUSBAND, S., KUBIKOVA, L., LEE, D., MELLO, C. V., POWERS, A., SIANG, C., SMULDERS, T. V., WADA, K., WHITE, S. A., YAMAMOTO, K., YU, J., REINER, A. and BUTLER, A. B. (2005). Avian brains and a new understanding of vertebrate brain evolution. Nat Rev Neurosci 6:151-159.

KALLEN, B. (1955). Cell degeneration during normal ontogenesis of the rabbit brain. J Anat 89:153-161.

KALLEN, B. (1965). Degeneration and regeneration in the vertebrate central nervous system during embryogenesis. Prog Brain Res 14:77-96.

KATZ, M. J. and LASEK, R. L. (1978). Evolution of the nervous system: role of ontogenetic buffer mechanisms in the evolution of matching populations. Proc Natl Acad Sci USA 75:1349-1352.

KELLY, K. J., SANDOVAL, R. M., DUNN, K. W., MOLITORIS, B. A. and DAGHER, P. C. (2003). A novel method to determine specificity and sensitivity of the TUNEL reaction in the quantitation of apoptosis. Am J Physiol Cell Physio/ 284:C1309-C1318.

KINGSBURY, M. A., REHEN, S. K., CONTOS, J. J. A., HIGGINS, C. M. and CHUN, J. (2003). Non-proliferative effects of lysophosphatidic acid enhance cortical growth and folding. Nat Neurosci6:1292-1299.

LABAT-MOLeUR, F., GUILleRMet, C., LORIMIER, P., ROBERT, C., LANTUEJOUL, S., BRAMBILLA, E. and NEGOESCU, A. (1998). TUNEL apoptotic cell detection in tissue sections: critical evaluation and improvement. $J$ Histochem Cytochem 46:327-334.

LAWSON, A., SCHOENWOLF, G. C., ENGLAND, M. A., ADDAI, F. K. and AHIMA, R. S. (1999). Programmed cell death and the morphogenesis of the hindbrain roof plate in the chick embryo. Anat Embryo/200:509-519.

NAVASCUÉS, J., MARTIN-PARTIDO, G., ALVAREZ, I. S. and RODRIGUEZGALLARDO, L. (1988). Cell death in suboptic necrotic centers of chick embryo diencephalon and their topographic relationship with the earliest fiber fascicles. $J$ Comp Neuro/278:34-46.

NAVASCUÉS, J., RODRIGUEZ-GALLARDO, L., GARCIA-MARTINEZ, V. ALVAREZ, I. S. and MARTIN-PARTIDO, G. (1987). Extra-axonal environment and fibre directionality in the early development of the chick embryo optic chiasm: a light and scanning electron microscopic study. J Neurocyto/16:299310.

NIKOLAKOPOULOU, A.M., PARPAS, A., PARNAGIS, L., ZIKOPOULOS, B., DERMON, C.R. (2006). Early post-hatching sex differences in cell proliferation and survival in the quail telencephalic ventricular zone and intermediate medial mesopallium. Brain Res Bull70:107-116.

OISHI, K., KAMAKURA, S., ISAZAWA, Y., YOSHIMATSU, T., KUIDA, K., NAKAFUKU, M., MASUYAMA, N. and GOTOH, Y. (2004). Notch promotes survival of neural precursor cells via mechanisms distinct from those regulating neurogenesis. Dev Bio/276:172-184.
OPPENHEIM, R. W. (1985). Naturally occurring cell death during neural development. Trends Neurosci 8:487-493.

PUELLES, L., AMAT, J. A. and MARTINEZ-DE-LA-TORRE, M. (1987). Segmentrelated, mosaic neurogenetic pattern in the forebrain and mesencephalon of early chick embryos: I. Topography of AChE-positive neuroblasts up to stage HH18. J Comp Neuro/266:247-268.

RAKIC, S. and ZECEVIC, N. (2000). Programmed cell death in the developing human telencephalon. Eur J Neurosci 12:2721-2734.

REINER, A., PERKEL, D. J., BRUCE, L. L., BUTLER, A. B., CSILLAG, A., KUENZEL, W., MEDINA, L., PAXINOS, G., SHIMIZU, T., STRIEDTER, G. F., WILD, M., BALL, G., DURAND, S., GUNTURKUN, O., LEE, D. W., MELLO, C. V., POWERS, A., WHITE, S. A., HOUGH, G., KUBIKOVA, L., SMULDERS, T. V., WADA, K., DOUGLAS-FORD, J., HUSBAND, S., YAMAMOTO, K., YU, J., SIANG, C. and JARVIS, E. D. (2004). Revised nomenclature for avian telencephalon and some related brainstem nuclei. J Comp Neuro/473:377-414.

SCHOOK, P. (1982). Cell action and cell interaction during ocular morphogenesis of the mammalian eye. In: Jakobiek F. A., editor. Ocular anatomy, embryology, and teratology. New York: Harper \& Row. p 121-141.

STRIEDTER, G. F. (1997). The telencephalon of tetrapods in evolution. Brain Behav Evol49:179-213.

TAKAMATSU, T. and FUJITA, S. (1987). Growth of notochord and formation of cranial and mesencephalic flexures in chicken embryo. Develop Growth and Diff 29:497-502.

THOMAIDOU, D., MIONE, M. C., CAVANAGH, J. F. R. and PARNAVELAS, J. G. (1997). Apoptosis and its relation to the cell cycle in the developing cerebral cortex. J Neurosci 17:1075-1085.

TSAI, H. M., GARBER, B. B. and LARRAMENDI, L. M. H. (1981). A 3H-thymidine autoradiographic analysis of telencephalic histogenesis in the chick embryo. I. Neuronal birthdates of telencephalic compartment in situ. J Comp Neurol 198:275-292.

VOYVODIC, J. T. (1996). Cell death in cortical development: how much? why? so what? Neuron 16:693-696.

WILKIE, A. L., JORDAN, S. A., SHARPE, J. A., PRICE, D. J. and JACKSON, I. J. (2004). Widespread tangential dispersion and extensive cell death during early neurogenesis in the mouse neocortex. Dev Bio/267:109-118.

YAGINUMA, H., TOMITA, M., TAKASHITA, N., MCKAY, S. E., CARDWELL, C., YIN, O. W. and OPPENHEIM, R. W. (1996). A novel type of programmed neuronal death in the cervical spinal cord of the chick embryo. $J$ Neurosci 16:3685-3703.

YEO, W. and GAUTIER, J. (2004). Early neural cell death: dying to become neurons. Dev Bio/274:233-244.

ZHANG, Z. and GALILEO, D. S. (1998). Widespread programmed cell death in early developing chick optic tectum. Neuroreport 9:2797-2801. 


\section{Supplementary Material}
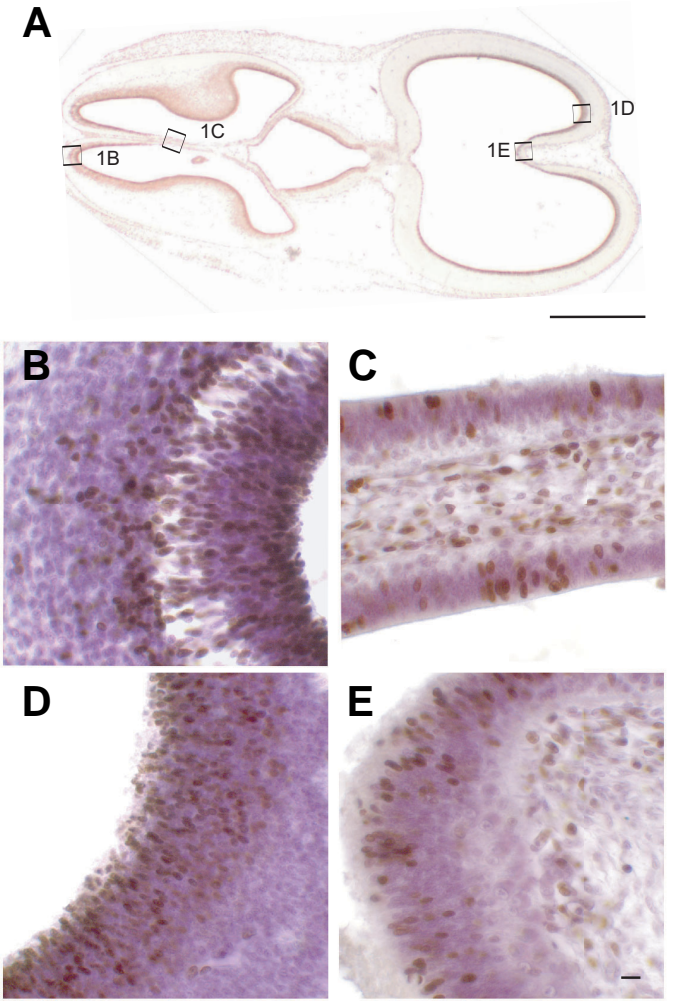

$\mathbf{F}$

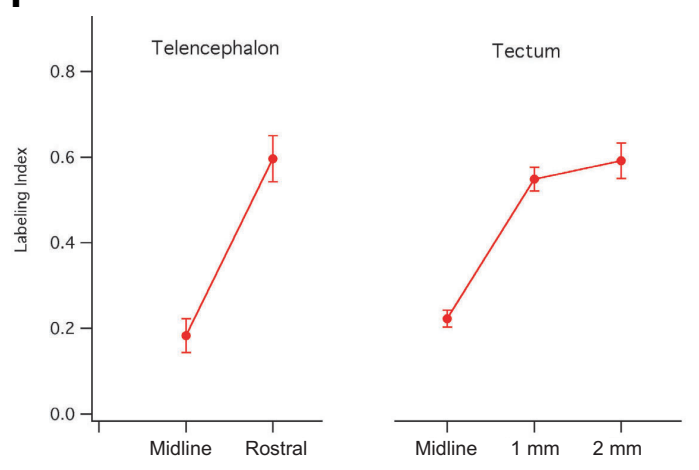

Supplementary Fig. 1. Cumulative BrdU labeling at stage 32. (A) Low magnification image of a horizontal section stained with anti-BrdU. Rectangles indicate the locations of higher power images shown in (B-E). (B) In the rostral tenelncephalon, most ventricular zone cells are BrdU+, giving a high labeling index. (C) At the telencephalic midline, the labeling index is significantly lower. (D) The tectum also exhibits a high labeling index away from the midline. (E) In contrast, at the tectal midline, the labeling index is low. (F) Graph illustrating that the labeling index increases with distance from the telencephalic and tectal midlines. Scale bars: (A) $1 \mathrm{~mm}$, (B-E) $10 \mu \mathrm{m}$.

\section{Related, previously published Int. J. Dev. Biol. articles}

See our recent Special Issue Ear Development edited by Fernando Giraldez and Bernd Fritzsch at: http://www.ijdb.ehu.es/web/contents.php?vol=51\&issue=6-7

See our Special Issue Developmental Morphodynamics edited by Lev Beloussov and Richard Gordon at: http://www.ijdb.ehu.es/web/contents.php?vol=50\&issue=2-3

DIx3 is expressed in the ventral forebrain of chicken embryos: implications for the evolution of the DIx gene family.

Hui Zhu and Andrew J. Bendall

Int. J. Dev. Biol. (2006) 50: 71-75

Notch activity is required to maintain floorplate identity and to control neurogenesis in the chick hindbrain and spinal cord.

Isabelle le Roux, Julian Lewis and David Ish-Horowicz Int. J. Dev. Biol. (2003) 47: 263-272

Getting your head around Hex and Hesx1: forebrain formation in mouse.

J P Martinez-Barbera and R S Beddington

Int. J. Dev. Biol. (2001) 45: 327-336

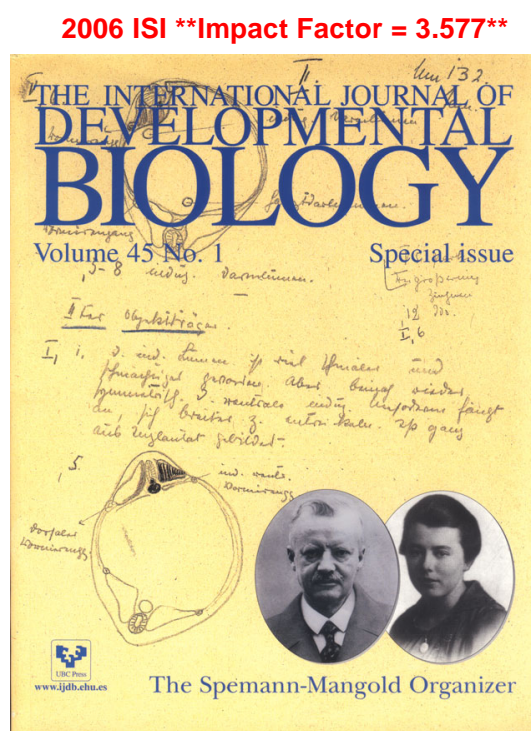

